\title{
Comparison of Perceived Quality of Life Between Children with Lupus Nephritis and Their Parents
}

\author{
Lasmauli Situmorang, M.D., Ahmad Suryawan, M.D., Ph.D., Ninik Asmaningsih Soemyarso,
} M.D., Ph.D.

Department of Child Health, Faculty of Medicine, Universitas Airlangga, Dr. Soetomo Hospital, Surabaya, East Java, 60286 Indonesia.

Received 26 February 2019 • Revised 14 June 2019 • Accepted 26 June 2019 • Published online 29 August 2019

\section{Abstract:}

Objective: The purpose of this study was to compare the score of quality of life between parents and children with lupus nephritis.

Material and Methods: A cross-sectional study was conducted from February to March 2017 in children with lupus nephritis aged 5-18 years old treated at the Department of Child Health Dr. Soetomo Surabaya Hospital. Quality of life was assessed from parents and children using the Pediatric Quality of Life Inventory (PedsQL) 4.0 Generic Core questionnaires. Statistical analysis of Wilcoxon signed rank test and pair t-test were used with $p$-value $<0.05$ being significant.

Results: A total of 30 children were included during the study period. Sixteen children were female with a mean age of 11.5 (standard deviation 2.7) years. The differences in score between parents and children were as follows: physical functioning (82.8 vs 87.5) $p$-value $=0.140$, emotional functioning (65.0 vs 72.5) $p$-value $=0.173$, social functioning (80.0 vs 95.0$) p-v a l u e=$ 0.016 and school functioning (67.5 vs 70.0) $p$-value=0.116. There were no differences according to onset of diagnosis and the only differences found were in social functioning based on the induction treatment phase. Children with complications showed significant differences in physical, emotional and social functioning ( $p$-value $=0.041, p-v a l u e=0.023, p-v a l u e=$ 0.038 respectively).

Conclusion: Parents and children with lupus nephritis showed different scores of quality of life in social functioning, and it is important to consider the daily life activities of children.

Keywords: children, lupus nephritis, PedsQL, quality of life

Contact: Ahmad Suryawan, M.D., Ph.D.

Department of Child Health, Faculty of Medicine, Universitas Airlangga,

Dr. Soetomo Hospital, Jl. Mayjen Prof. Dr. Moestopo No.6-8, Surabaya,

Jawa Timur 60286 Indonesia.

E-mail: ahmad.suryawan@fk.unair.ac.id
J Health Sci Med Res 2019;37(4):281-287 doi: 10.31584/jhsmr.201962 www.jhsmr.org 


\section{Introduction}

Lupus nephritis is a common and often severe manifestation of the chronic autoimmune vasculitis that occurs in systemic lupus erythematosus (SLE). ${ }^{1}$ Approximately $60.0-80.0 \%$ of children with SLE have urinary or renal function abnormalities, which in $90.0 \%$ occurs within two years of onset. ${ }^{2}$ The prevalence of lupus nephritis is 3.64 per 100,000 children and the annual incidence is 0.72 cases per 100,000 per year. ${ }^{3}$

Lupus nefritis usually occurs during adolescence; it is uncommon before the age of 10 years and very rare before 5 years. Children have a long life expectancy and therefore any effort should be made to optimize treatment and prevent morbidity. ${ }^{2}$ Lupus nephritis interferes with many aspects of normal life. Unlike adults, children with lupus nefritis have to face the consequences of this chronic disease during childhood and adolescencevulnerable periods in their intellectual and emotional development, and it can affect quality of life. ${ }^{4}$

Quality of life is a subjective personal perception of living with the disease. It can be different between children and their parents. ${ }^{5}$ Pediatric Quality of Life Inventory (PedsQL) 4.0 Generic Core is one of the instruments used to measure quality of life, and it is specifically designed to measure the core health dimensions that can be used with healthy children and those with acute and chronic health conditions. ${ }^{5,6}$ Quality of life may be influenced by onset of disease, treatment and complications.

The aim of this study was to compare the score of quality of life between parents and children with lupus nephritis.

\section{Material and Methods}

A cross-sectional study was conducted from February to March 2017. Children with lupus nephritis aged 5-18 years old treated at the Nephrology Division,
Department of Child Health of Dr. Soetomo Surabaya Hospital were collected by total population sampling. Children with unstable conditions were excluded. Written informed consent was obtained from parents.

Quality of life using PedsQL 4.0 Generic Core was assessed from each parent and child's questionnaires. The PedsQL 4.0 Generic Core, which is divided into 4 functions (physical, emotional, social and school function), is a multidimensional intrument that is reliable and valid in healthy populations and in children with acute and chronic conditions. Quality of life score between children and parents was compared according to the onset of disease, treatment phase and complications. Higher scores indicate a better quality of life. Statistical analysis of Wilcoxon signed rank test and pair t-test were used with $p$-value $<0.05$ being significant. The Research Ethics Committee of the Dr. Soetomo Surabaya Hospital approved this study.

\section{Results}

A total of 30 children were included during the study period. Most of them (16/30) were female with a mean age of 11.5 [standard deviation (S.D.) 2.7] years. Table 1 shows the characteristics of subjects. The mean age of parents was $36.8 \pm 6.8$ years, and $86.7 \%$ of the questionnaire was completed by mothers. The highest educational level of parents was elementary school and most of the parents were housewives.

The most common clinical manifestation was edema (73.3\%), followed by pale/weak (63.3) and hematuria (36.7). The complication of acute kidney injury was the most common complication (46.1\%) followed by hypertensive crisis $(23.1 \%)$. The quality of life scores reported by children tended to be lower than those reported by parents for all functions; however, only social functioning was statistically significant $(p-$ value $=0.016)$ (Table 2$)$. 
Table 1 Subject charateristics of lupus nephritis children

\begin{tabular}{lc}
\hline Charateristic & $\mathrm{n}=\mathbf{3 0}$ \\
\hline Age (years), mean (S.D.) & $11.5(2.7)$ \\
Sex, $\mathrm{n}(\%)$ & \\
$\quad$ Girl & $16(53.3)$ \\
$\quad$ Boys & $14(46.7)$ \\
Onset diagnosis, $\mathrm{n}(\%)$ & \\
$\quad \leq 10$ years & $12(40.0)$ \\
$>10$ years & $18(60.0)$ \\
Duration of illness, $\mathrm{n}(\%)$ & \\
Induction phase & $19(63.3)$ \\
$\quad$ Maintenance phase & $11(36.7)$ \\
Presence of complication, $\mathrm{n}(\%)$ & \\
Yes & $13(43.3)$ \\
$\quad$ No & $17(56.7)$ \\
Type of complication, $\mathrm{n}(\%)$ & \\
Acute kidney injury & $6(46.1)$ \\
Chronic kidney injury & $1(7.7)$ \\
Hypertensive crisis & $3(23.1)$ \\
Others & $3(23.1)$ \\
\hline
\end{tabular}

The comparison of quality of life scores between children with lupus nephritis and their parents according to the onset of the disagnosis ( $\leq 10$ years and $>10$ years) showed no significant difference in all functions. Accord- ing to the duration of illness, the quality of life reported by parents was higher than in children on social functioning in the "induction phase" ( $p$-value=0.024), whereas in the "maintenance phase" no significant difference was found in all functions. According to the presence of complications, the scores of quality of life on physical ( $p$-value $=0.041$ ), emotional $(p-$ value $=0.023)$ and social $(p-$ value $=0.038)$ functioning of children lupus nephritis with complications were significantly different, whereas there was no significant difference in the non-complication group (Table 3).

\section{Discussion}

There are lots of studies that explain lupus nephritis/ systemic lupus erythematosus, but most of them are mainly focused on adults ${ }^{7-9}$, not children. The mean age of children with lupus nephritis in our study was 11.5 (S.D. $2.7)$, and most were female $(16 / 30)$. This finding is in accordance with the study by Hiraki et $\mathrm{al}^{10}$ who found that the average age of children was 13.1 (S.D. 3.2), but in contrast it was different from the previous study which found a younger age of 6.4 (S.D. 3.2) ${ }^{11}$, even though the female sex was the most prevalent in both of these studies.

Table 2 Comparison of the quality of life between children with lupus nephritis and their parents

\begin{tabular}{|c|c|c|c|}
\hline Domain & $\begin{array}{l}\text { Children report } \\
\text { median (min-max) }\end{array}$ & $\begin{array}{l}\text { Parents report } \\
\text { median (min-max) }\end{array}$ & p-value \\
\hline Physical functioning & $82.8(31.2-100.0)$ & $87.5(25.0-100.0)$ & $0.140 *$ \\
\hline Emotional functioning & $65.0(30.0-100.0)$ & $72.5(25.0-100.0)$ & $0.173^{\star *}$ \\
\hline Social functioning & $80.0(30.0-100.0)$ & $95.0(40.0-100.0)$ & $0.016^{*}$ \\
\hline School functioning & $67.5(30.0-100.0)$ & $70.0(30.0-95.0)$ & $0.116^{\star \star}$ \\
\hline
\end{tabular}

*Wilcoxon signed rank test, ${ }^{* *}$ paired t-test, $p$-value $<0.05$, min=minimal, max=maximal 
Quality of life is a personal perception and it is subjective $^{12}$, and therefore perceptions between parents and children in this study can be different. Although subjective, quality of life can be measured. The PedsQL 4.0 Generic Core is one of the instruments used to measure quality of life in healthy and unhealthy children with lupus nephritis ${ }^{13}$ and consists of questions that can be answered by both children and parents. ${ }^{6}$ Children with a chronic illness can affect the quality of life of their family including parents, and it can make for a different perception between them. ${ }^{14}$

In this study, according to the children's reports, the highest score was in physical functioning while the lowest score was in emotional functioning. A study by Louthrenoo et $\mathrm{al}^{15}$, showed that systemic lupus erythematosus in children affects their physical and psychosocial functioning. A study by Bai et $\mathrm{al}^{16}$, revealed that physical and psychosocial scores in children with only one condition were lower than for children without chronic conditions ( $p$-value<0.05). High physical functioning scores in children in this study may be because they feel that they can still carry out daily activities like healthy children. Children with chronic diseases that interfere with physical activity can have an influence on emotional and behavioral problems ${ }^{17,18}$; thus, in this study emotional scores were indeed low. Emotional disorders can also occur due to medical care trauma. ${ }^{19}$

Children with lupus nephritis need regular care and routine check ups, and have significantly higher school absence rates than the general population; however, children with lupus nephritis have higher cognitive function than children with other kidney disorders. ${ }^{20}$ In this study, the significant differences found were only in social functioning, which could be because parents felt that their children did not have social problems while the children actually felt they had problems with peers both at home and school.

The younger the age when diagnosed with lupus nephritis, the more severe the clinical manifestations shown. Children with lupus nephritis show more severe symptoms than adults ${ }^{21,22}$, nevertheless differences in quality of life based on the onset of diagnosis were not found.

Duration of illness could be divided into two phases: the induction phase and the maintenance phase. In the induction phase, corticosteroid administration is given in 6 months with high doses every month, whereas in the maintenance phase corticosteroid administration begins to be tapered off. ${ }^{23}$ Differences in quality of life scores in social functioning in the induction phase are related to differences in quality of life between parents and children in general. Children with chronic diseases have psychosocial problems; besides getting corticosteroids, children also get immunosuppression treatment. In this study the type of immunosuppression treatment was not studied; however, the administration of sitostatics can cause differences in quality of life..$^{24,25}$

The assessments of quality of life in the complication groups in this study were significantly different between children and their parents in physical, emotional and social functioning, in which parents showed higher scores. Complications that occurred in this study were acute kidney injury, chronic kidney disease and hypertensive crisis. Previous research has suggested that lupus nephritis is associated with end-stage renal failure ${ }^{26}$, and the quality of life in children with chronic kidney disease shows lower physical, emotional, social and school scores. ${ }^{27}$ A study by Gannoni showed that despite dealing with serious and potentially life threatening situations, parents and children took positive steps to cope with their challenges, and also perceived positive aspects of living with a childhood chronic illness. Individual or family interventions may also be considered more appropriate given the strong emotions described (and often expressed) by participants. It seems important to provide both parents and children with opportunities to discuss and practise their emotional expressiveness and regulation, and an individual or family setting may be considered more appropriate for privacy reasons. ${ }^{14}$ 


\section{Conclusion}

Lupus nephritis is a chronic disease that can affect all aspects of a patient's life. The quality of life in patients with lupus nephritis is lower than in the general population, even though it could be personal perception that is different for each person. Parents and children with lupus nephritis showed different scores of quality of life in social functioning, and it is important to consider the daily life activities of children. Understanding their child's perception was significant for parents in order to help their child recover from lupus nephritis.

\section{Acknowledgement}

We would like to thank Windhu Purnomo, M.D. Ph.D. who supported the statistical analysis in this study.

\section{Conflict of interest}

None declared.

\section{References}

1. Zubair A, Frieri M. Lupus nephritis: review of the literature. Curr Allergy Asthma Rep 2013;13:580-6.

2. Perfumo F, Martini A. Lupus nephritis in children. Lupus 2005;14: 83-8.

3. Hiraki LT, Feldman CH, Liu J, Alarcon GS, Fischer MA, Winkelmayer WC, et al. Prevalence, incidence, and demographics of systemic lupus erythematosus and lupus nephritis from 2000 to 2004 among children in the US Medicaid beneficiary population. Arthritis Rheum 2012;64:2669-76.

4. Kamphuis S, Silverman ED. Prevalence and burden of pediatric-onset systemic lupus erythematosus. Nat Rev Rheumatol 2010;6:538-46.

5. Hullmann SE, Ryan JL, Ramsey RR, Chaney JM, Mullins LL. Measures of general pediatric quality of life: Child Health Questionnaire $(\mathrm{CHQ})$, DISABKIDS Chronic Generic Measure (DCGM), KINDL-R, Pediatric Quality of Life Inventory (PedsQL) 4.0 Generic Core Scales, and Quality of My Life Questionnaire (QoML). Arthritis Care Res 2011;63(Suppl 11):S420-30.
6. Varni JW, Limbers CA, Burwinkle TM. Impaired health-related quality of life in children and adolescents with chronic conditions: a comparative analysis of 10 disease clusters and 33 disease categories/severities utilizing the PedsQL ${ }^{m} 4.0$ Generic Core Scales. Health Qual Life Outcomes 2007;5:43.

7. Ruperto N, Buratti S, Duarte-Salazar C, Pistorio A, Reiff A, Bernstein $B$, et al. Health-related quality of life in juvenileonset systemic lupus erythematosus and its relationship to disease activity and damage. Arthritis Rheum 2004;51:458-64.

8. Levy DM, Peschken CA, Tucker LB, Chedeville G, Huber AM, Pope JE, et al. Health related quality of life in childhoodonset systemic lupus erythematosus is associated with ethnicity: results from a multiethnic multicenter canadian cohort. Arthritis Care Res 2014;66:1767-74.

9. Chaigne B, Chizzolini C, Perneger T, Trendelenburg M, Huynh-Do $\mathrm{U}$, Dayer E, et al. Impact of disease activity on health-related quality of life in systemic lupus erythematosus - a crosssectional analysis of the swiss systemic lupus erythematosus cohort study (SSCS). BMC Immunology 2017;18:17-26.

10. Hiraki LT, Benseler SM, Tyrrell PN, Hebert D, Harvey E, Silverman ED. Clinical and laboratory characteristics and long-term outcome of pediatric systemic lupus erythematosus: a longitudinal study. J Pediatr 2008;152:550-6.

11. Abdalla E, Jeyaseelan L, Ullah I, Abdwani R. Growth pattern in children with systemic lupus erythematosus. Oman Med $\mathrm{J}$ 2017;32:284-90.

12. Karimi M, Brazier J. Health, health-related quality of life, and quality of life: what is the difference? Pharmacoeconomics 2016;34: 645-9.

13. Moorthy LN, Peterson MG, Harrison MJ, Onel KB, Lehman TJ. Quality of life in children with systemic lupus erythematosus: a review. Lupus 2007;16:663-9.

14. Gannoni AF, Shute RH. Parental and child perspectives on adaptation to childhood chronic illness: a qualitative study. Clin Child Psychol Psychiatry 2010;15:39-53.

15. Louthrenoo O, Krairojananan J, Chartapisak W, Opastirakul S. Psychosocial functioning of children with systemic lupus erythematosus. J Paediatr Child Health 2012;48:1091-4.

16. Bai G, Herten MH, Landgraf JM, Korfage IJ, Raat H. Childhood chronic conditions and health-related quality of life: findings from a large population-based study. PloS One 2017;12: doi: 10.1371/journal.pone.0178539. 
17. Pinquart $M$, Shen $Y$. Behavior problems in children and adolescents with chronic physical illness: a meta-analysis. J Pediatr Psychol 2011;36:1003-16.

18. Jolly M, Toloza S, GokerB, Clarke AE, Navarras SV, Wallaces $D$, et al. Disease-specific quality of life in patients with lupus nephritis. Lupus 2017;27:257-64.

19. Turkel S, Pao M. Late consequences of chronic pediatric illness. Psychiatr Clin North Am 2007;30:819-835.

20. Knight A, Kogon AJ, Matheson MB, Warady BA, Furth SL, Hooper SR. Cognitive function in children with lupus nephritis: a cross-sectional comparison with children with other glomerular chronic kidney diseases. J Pediatr 2017;189:181-8.

21. Pluchinotta FR, Schiavo B, Vittadello F, Martini G, Perilongo G, Zulian F. Distinctive clinical features of pediatric systemic lupus erythematosus in three different age classes. Lupus 2007;16:550-5.

22. Sato VA, Marques ID, Goldenstein PT, Carmo LP, Jorge LB, Titan SM, et al. Lupus nephritis is more severe in children and adolescents than in older adults. Lupus 2012;21:978-83.

23. Teo S, Lu PY, Liu ID, Yap HK. Management of Lupus nephritis in children. In: Yap HK, Liu ID, Ng KH, editors. Pedatric nephrology on the go. $3^{\text {th }}$ ed. Singapore: Shaw-NKF-NUH Children’s Kidney Center; 2018;p.295-313.

24. Tse KC, Tang CS, Lio WI, Lam MF, Chan TM. Quality of life comparison between corticosteroid-and-mycofenolate mofetil and corticosteroid- and-oral cyclophosphamide in the treatment of severe lupus nephritis. Lupus 2006;15:371-9.

25. Tian SY, Silverman ED, Pullenayegum E, Brown PE, Beyene J, Feldman BM. Comparative effectiveness of mycophenolate mofetil for the treatment of juvenile-onset proliferative lupus nephritis. Arthritis Care Res 2017;69: 1887-94.

26. Hiraki LT, Lu B, Alexander SR, Shaykevich T, Alarcon GS, Solomon DH, et al. End-stage renal disease due to lupus nephritis among children in the US, 1995-2006. Arthritis Rheum 2011;63:1988-97.

27. Gerson AC, Wentz A, Abraham AG, Mendley SR, Hooper SR, Butler RW, et al. Health related quality of life of children with mild to moderate chronic kidney disease. Pediatrics 2010;125: e349-57. 